\title{
Valentina Lepri - Maria Elena Severini, Jacopo Corbinelli editore 'politico' alla corte di Francia: il caso della «princeps» dei "Ricordi" di Guicciardini
}

\section{Filippo Fassina}

\author{
(2) OpenEdition \\ Journals \\ Edizione digitale \\ URL: http://journals.openedition.org/studifrancesi/8870 \\ DOI: $10.4000 /$ studifrancesi.8870 \\ ISSN: 2421-5856 \\ Editore \\ Rosenberg \& Sellier
}

\section{Edizione cartacea}

Data di pubblicazione: 1 octobre 2008

Paginazione: 443

ISSN: 0039-2944

\section{Notizia bibliografica digitale}

Filippo Fassina, «Valentina Lepri - Maria Elena Severini, Jacopo Corbinelli editore 'politico' alla corte di Francia: il caso della "princeps» dei "Ricordi" di Guicciardini», Studi Francesi [Online], 155 (LII | II) | 2008, online dal 30 novembre 2015, consultato il 12 janvier 2021. URL: http://journals.openedition.org/ studifrancesi/8870 ; DOI: https://doi.org/10.4000/studifrancesi.8870

Questo documento è stato generato automaticamente il 12 janvier 2021.

\section{cc) (†) $\odot$}

Studi Francesi è distribuita con Licenza Creative Commons Attribuzione - Non commerciale - Non opere derivate 4.0 Internazionale. 


\title{
Valentina Lepri - Maria Elena Severini, Jacopo Corbinelli editore 'politico' alla corte di Francia: il caso della «princeps» dei "Ricordi" di Guicciardini
}

\author{
Filippo Fassina
}

\section{NOTIZIA}

VALENTINA LEPRI - MARIA ELENA SEVERINI, Jacopo Corbinelli editore 'politico' alla corte di Francia: il caso della «princeps» dei "Ricordi” di Guicciardini, («Rinascimento»), XLVI, 2006, pp. 497-555.

Nella prima parte di questo lavoro, filologicamente attento, le due studiose, inserendo l'attività editoriale di Corbinelli nel quadro degli intenti di italianizzazione della cultura francese che contraddistinguono la corte dei Valois sotto Caterina de' Medici, evidenziano il carattere politico, nel senso propagandistico e di partecipazione agli avvenimenti del momento (le guerre di religione), che rivestono sia l'opera di editore sia le scelte di testi da immettere nella circolazione francese. Nella seconda parte del contributo si affrontano, invece, questioni puramente filologiche, con lo scopo di determinare i manoscritti dei Ricordi utilizzati da Corbinelli nella sua edizione uscita nel 1576 per i tipi di Frédéric Morel. Quest'ultima parte è supportata da un'approfondita disamina dei testi e delle varianti, e corredata da un'ampia appendice che offre la trascrizione e l'analisi filologica, per i primi cinquanta ricordi, sia della cinquecentina, sia dei manoscritti. 